\title{
Editorial
}

\section{Cauda Equina Syndrome: A Simple Entity with Lot of Enigma!}

\author{
Abrar Wani ${ }^{1}$ Ayub Thoker ${ }^{1}$ \\ ${ }^{1}$ Department of Neurosurgery, Sher-i-Kashmir Institute of Medical \\ Sciences, Srinagar, Jammu and Kashmir, India \\ Indian J Neurosurg 2018;7:173-175
}

Lumbar disc protrusion was first described by Luschka in 1858. ${ }^{1}$ It was another 50 years before the first discectomy took place and another 30 years until Mixter and Barr described the syndrome of cauda equina compression (CES). ${ }^{2}$ It is fortunately a rare condition with a reported incidence of approximately 1 per 100,000/year affecting 2 to 3\% of lumbar disc operations. ${ }^{3}$

On searching the literature, we find a lot of confusion and controversy over the definition of CES. Garfin defined it as a rare condition caused by compression of several nerve roots of the cauda equine (CE), including the lower sacral nerves influencing the bladder, rectal, and genital function, most often due to a herniated disc. ${ }^{4}$ Its classic presentation consists of loss of sensation of the saddle area, sphincter dysfunction (bladder and/or bowel), and/or sexual dysfunction, often in combination with motor deficit with or without reflex changes of the lower limbs. ${ }^{4} \mathrm{CE}$ nerve roots provide the sensory and motor innervations of most of the lower extremities, pelvic floor, and sphincters. Symptoms may present in different combinations and at varied times. Fraser et $\mathrm{al}^{3}$ reviewed 105 articles and proposed a single definition of CES. For the diagnosis of CES, one or more of the following must be present along with severe low backache: (1) bladder and/or bowel dysfunction, (2) reduced sensation in the saddle area, and (3) sexual dysfunction, with possible neurologic deficit in the lower limb (motor/sensory loss, reflex change).

Another useful classification is CES as complete and incomplete. Complete syndrome is characterized by painless urinary retention and overflow incontinence with complete or near-complete saddle and genital sensory loss. Incomplete syndrome is characterized by varied urinary difficulties in form of poor urinary stream, need to strain for urination, and partial or unilateral saddle and genital sensory deficit..$^{5}$ On the basis of speed of onset of symptoms, CES has been classified into three groups: rapid onset without a previous history of back problems, acute bladder dysfunction with a history of

Address for correspondence Abrar Ahad Wani, MCh, Additional Professor, Department of

Neurosurgery, Sher-i-Kashmir Institute of Medical Sciences, Soura, Srinagar 190011, Jammu and Kashmir, India (e-mail: drabrarahadwani@gmail.com). low back pain and sciatica, and chronic backache and sciatica with gradually progressing CES often with canal stenosis. ${ }^{6}$ When the syndrome is incomplete (CES-incomplete), the patient has urinary difficulties of neurogenic origin, including altered urinary sensation, loss of desire to void, poor urinary stream, and need to strain to micturate. ${ }^{5}$ There is partial or unilateral saddle and genital sensory deficit. Trigone sensation is present. Complete syndrome (CES-retention) is characterized by extensive or complete saddle and genital sensory deficit with deficient trigone sensation.

Etiology of CES is variable, with the most common cause being disc prolapse. Other pathologies that can cause CES include spinal stenosis, hematoma, trauma, tumor, infection, fracture, and inflammatory conditions. ${ }^{3,4,6}$ In all of these, we find the common component of compression of CE. Clinical signs offer valuable guide to diagnosis; however, suspicion should be confirmed with magnetic resonance imaging.

The pathogenesis and natural history of CES is not clearly defined. One hypothesis is that large central or paracentral disc prolapses cause extrinsic compression of the lumbosacral nerve roots below the level of the conus medullaris. ${ }^{7}$ It is not clear what quantifies significant canal compression leading to CES. In many patients, there is extensive canal stenosis and yet they do not have CES while with much less canal compromise, CES may be seen. CES has been reported with less than $25 \%$ canal compromise. This leads to another hypothesis that CES is chemical mediated with inflamed and edematous neural structures being found on pathologic samples. CES may result from any damage to the CE nerve roots such as direct mechanical compression, inflammation, and venous congestion or ischemia. The vascular supply of $\mathrm{CE}$ nerve roots is derived from arteries that run along the anterior and posterior roots (the fifth lumbar artery arises from iliolumbar artery; the first sacral artery arises from lateral superior sacral artery, which is a branch of the hypogastric artery). These arteries that accompany each nerve are "end" arteries with no effective anastomotic connections so that a compression at
DOI https://doi.org/ 10.1055/s-0038-1676902 ISSN 2277-954X.
(C)2018 Neurological Surgeons' Society of India
License terms

(우요 $\Theta$ 
any point may result in ischemia of the portion of the nerve root supplied by the end artery. CE nerve roots are located inside the dural sac, which is filled with cerebrospinal fluid (CSF). A decrease in the cross-sectional area of the dural sac to $36 \%$ (e.g., by a compressive etiology) leads to an elevation of the pressure among the nerve roots of $50 \mathrm{~mm} \mathrm{Hg}$, which can lead to irreversible damage to these nerves. It has been proven experimentally that a constriction of greater than $50 \%$ of the cross-sectional area represents a critical point that results in neurologic deficits and histologic abnormalities. ${ }^{8-10}$

Clinical diagnosis of CES is not easy and most cases are of sudden onset and progress rapidly within hours or days. CES can present with a myriad of symptoms. These include back pain, lower extremity and perineal sensory deficit, leg pain, leg weakness, and disturbance of bladder and bowel function. Urinary dysfunction may include retention, difficulty in starting or stopping a stream of urine, overflow incontinence, and decreased bladder and urethral sensation. Bowel disturbances may include fecal incontinence and constipation. Rectal examination may reveal loss of anal tone and sensation. Subsequently the clinical diagnosis of CES lacks sensitivity and specificity, with no single symptom or sign adequately predicting management or outcome., ${ }^{9,11}$ Sexual dysfunction and bilateral leg symptoms in the form of radicular pain, numbness, or weakness are indicative of partial or impending CES if not part of the syndrome itself. CES affects males and females equally and can occur at any age but primarily in adulthood. $8,9,11$

There is consensus that the surgery is the treatment for CES, but what kind of surgery is the best for the patient is debatable. Some people continue to do minimally invasive procedures as are done in the standard disc surgery. However, some suggest that surgical exposure should generally be via full laminectomy rather than microdiscectomy. Permanent damage can result from excessive manipulation of the dura, and occasionally transthecal excision may be necessary. ${ }^{5}$

There is lot of controversy regarding the timing of intervention. It seems apparently that early surgery is necessary for better prognosis, and this was suggested by Shepherd. ${ }^{7}$ However, in this study, no clear-cut definition of early surgery was defined. Ahn et al in an extensive meta-analysis of 42 publications found that a significant improvement in sensory and motor deficits as well as urinary and rectal function occurred in patients who underwent decompression within 48 versus after 48 hours. ${ }^{12}$ Kohleas et al suggested that there was further benefit in treating patients within 24 hour, rather than 48 hours. ${ }^{13}$ The point is made that in experimental work in primates and in other clinical situations, nerve ischemia for more than around 6 hours is irreversible. In addition, operating in this short window period is practically impossible, so the outcome of CES is practically decided by the time the patient is admitted to hospital. ${ }^{5}$ However, one must strive to give patient decompression as early as possible to prevent the ongoing damage or at least to provide a chance to recover from the damage already caused in spite of no class I evidence to support this view. Crocker et al added a point further that often emergency surgery is done in night by inexperienced staff and that may not be in the patient's best interest. Besides, the cost of management will be very high if surgery is done on emergency basis round the clock, so the surgery must be done on "urgent basis" and not on "emergency basis."14 Heyes et al in 2018 did a study on influence of timing of surgery on CES: They found no clear evidence that timing of surgery negatively influenced outcome following surgical decompression for CES. They suggested that the most important factor for outcome assessment was the completeness of deficit at presentation, but this does not imply that patients should be left to progress to complete deficit if they have partial., ${ }^{715}$

Regarding prognosis, again the results are varied. However, on average $70 \%$ patients have acceptable recovery, but the remaining ones are very upset regarding their bladder and sexual dysfunction. Invariably patients have some residual motor or sensory symptoms in perineum and lower limbs even if they have acceptable recovery. ${ }^{5,7}$

\section{Conflicts of Interest}

None declared.

\section{References}

1 Luschka H. Die Halbgelenke des menschlichen Körpers. Eine Monographie. Berlin, Germany: Reimer; 1858

2 Oppenheim $\mathrm{H}$, Krause F. Über einklemmung bzw: strangulation der cauda equina. Dtsch Med Wochenschr 1909;35:697-700

3 Fraser S, Roberts L, Murphy E. Cauda equina syndrome: a literature review of its definition and clinical presentation. Arch Phys Med Rehabil 2009;90(11):1964-1968

4 Garfin SR, Rydevik BL, Brown RA. Compressive neuropathy of spinal nerve roots. A mechanical or biological problem? Spine 1991;16(2):162-166

5 Gleave JRW, Macfarlane R. Cauda equina syndrome: what is the relationship between timing of surgery and outcome? $\mathrm{Br} \mathrm{J}$ Neurosurg 2002;16(4):325-328

6 Tandon PN, Sankaran B. Cauda equina syndrome due to lumbar disc prolapse. Indian J Orthop 1967;1:112-119

7 Shephard RH. Diagnosis and prognosis of cauda equina syndrome produced by protrusion of lumbar disk. BMJ 1959;2(5164):1434-1439

8 Bell DA, Collie D, Statham PF. Cauda equina syndrome: what is the correlation between clinical assessment and MRI scanning? Br J Neurosurg 2007;21(2):201-203

9 Lavy C, James A, Wilson-MacDonald J, Fairbank J. Cauda equina syndrome. BMJ 2009;338:b936

10 Alam S, Wani AA, Ramzan AU, Dar TI, Malik NK. Efficacy of canal compromise and canal clearance in predicting outcome after spinal injury. Neurosurg Q 2010;20(3):199-202

11 Gardner A, Gardner E, Morley T. Cauda equina syndrome: a review of the current clinical and medico-legal position. Eur Spine J 2011;20(5):690-697

12 Ahn UM, Ahn NU, Buchowski JM, Garrett ES, Sieber AN, Kostuik JP. Cauda equina syndrome secondary to lumbar disc herniation: a meta-analysis of surgical outcomes. Spine 2000;25(12):1515-1522

13 Kohles SS, Kohles DA, Karp AP, Erlich VM, Polissar NL. Timedependent surgical outcomes following cauda equina syndrome diagnosis: comments on a meta-analysis. Spine 2004;29(11):1281-1287 
14 Crocker M, Fraser G, Boyd E, Wilson J, Chitnavis BP, Thomas NW. The value of interhospital transfer and emergency MRI for suspected cauda equina syndrome: a 2-year retrospective study. Ann R Coll Surg Engl 2008;90(6):513-516
15 Heyes G, Jones M, Verzin E, McLorinan G, Darwish N, Eames $\mathrm{N}$. Influence of timing of surgery on cauda equina syndrome: outcomes at a national spinal centre. J Orthop 2018;15(1):210-215 